\title{
A regulação de aditivos que conferem sabor e aroma aos produtos derivados do tabaco no Brasil
}

The regulation of addictives and flavors on tobacco products in Brazil

\section{Silvana Rubano Barretto Turci}

Farmacêutica, mestre em Toxicologia e doutora em Saúde Pública. Pesquisadora do Centro de Estudos sobre Tabaco e Saúde, da Fundação Oswaldo Cruz (Cetab/Ensp/Fiocruz), Rio de Janeiro, Brasil.

\section{Valeska Carvalho Figueiredo}

Médica, mestre e doutora em Saúde Coletiva. Pesquisadora do Centro de Estudos sobre Tabaco e Saúde, da Fundação Oswaldo Cruz (Cetab/Ensp/Fiocruz), Rio de Janeiro, Brasil.

\section{Vera Luiza da Costa e Silva}

Médica, doutora em Ciências da Saúde; MBA Saúde; consultora da Organização Mundial de Saúde; pesquisadora visitante da Escola Nacional de Saúde Pública da Fundação Oswaldo Cruz (Ensp/Fiocruz) e Coordenadora do Centro de Estudos sobre Tabaco e Saúde (Cetab/Ensp/Fiocruz), Rio de Janeiro, Brasil.

Resumo: A Agência Nacional de Vigilância Sanitária (ANVISA) proibiu, por meio da Resolução da Diretoria Colegiada $n^{\circ} 14$, de 2012, o uso de aditivos que conferem aroma e sabor aos produtos derivados do tabaco, com o objetivo de reduzir a experimentação e iniciação por crianças e jovens já que o emprego dessas substâncias, que caracterizam sabores e reduzem a aspereza da fumaça, os tornam mais atraentes e palatáveis. A Organização Mundial da Saúde (OMS) considera o tabagismo como uma doença pediátrica pois $90 \%$ dos fumantes começam a fumar antes dos 19 anos e quanto mais cedo se iniciam no uso do tabaco, mais rapidamente eles se tornam dependentes. No Brasil, os custos do tratamento das doenças tabaco-relacionadas chegam a R $\$ 21$ bilhões/ano. Proibir os aditivos é uma importante medida de saúde pública, em consonância com os artigos 9 e 10 e Guias Parciais de Implementação da Convenção-Quadro para o Controle do Tabaco da OMS (CQCT/OMS), tratado ratificado pelo Brasil em 2005. Esses artigos versam sobre a regulamentação do conteúdo e a divulgação de informações dos produtos do tabaco, respectivamente. O artigo faz uma análise do processo regulatório no Brasil, elencando os principais eventos relacionados e sugerindo uma interferência direta da indústria fumageira e de grupos de interesse na tomada de decisão e na implementação da RDC14/2012. Apesar do esforço da Anvisa e de pareceres favoráveis da Advocacia Geral da União e da Procuradoria Geral da República quanto à constitucionalidade da medida, a indústria do tabaco tem procurado adiar sua entrada em vigor, prevista para setembro/2013, mas ainda pendente de decisão do Supremo Tribunal Federal.

Palavras chaves: tabaco; regulamentação de produtos do tabaco; proibição de aditivos. 
Resumen: La Agencia Nacional de Vigilancia Sanitaria (ANVISA) prohibió, a través de resolución (RDC $n^{\circ} 14$, de 2012), el uso de aditivos que imparten sabor y gusto a los productos de tabaco, con el objetivo de reducir su experimentación e iniciación por los niños y jóvenes desde que el uso de tales sustancias, que les dan sabores y reducen la dureza del humo, los hace más atractivos y apetecibles. La Organización Mundial de la Salud (OMS) considera el tabaquismo como una enfermedad pediátrica porque el $90 \%$ de los fumadores empiezan a fumar antes de los 19 años, y mientras más pronto comience el uso del tabaco, más rápidamente se convierten en adictos. En Brasil, los costos del tratamiento de las enfermedades relacionadas con el tabaco lleguen a 21 billones de dólares al año. Prohibir aditivos en los productos de tabaco es una importante medida de salud pública, de conformidad con los artículos 9 y 10 y Guías de Implementación Parcial del Convenio Marco para el Control del Tabaco de la OMS (CMCT/OMS), tratado ratificado por Brasil en 2005. Tales artículos lidian con la regulación de contenidos y divulgación de los productos del tabaco, respectivamente. El artículo analiza el proceso de regulación de aditivos en productos de tabaco en Brasil, lista los principales acontecimientos relacionados y sugiere una interferencia directa de la industria tabacalera y de grupos de interés en la toma de decisiones e implementación de la RDC14/2012. A pesar de los esfuerzos de Anvisa y de opiniones favorables de la Procuraduría General y de la Fiscalía General sobre la constitucionalidad de la medida, la industria tabacalera ha tratado de retrasar su entrada en vigor, aún pendiente ante el Supremo Tribunal Federal.

Palabras clave: tabaco; regulación de los productos de tabaco; prohibición de los aditivos.

Abstract: The National Agency for Health Surveillance (ANVISA) banned through Resolution (RDC14/2012) the use of additives and flavors in tobacco products in Brazil with the aim to reduce the experimentation and initiation by children and young people, making them less attractive and palatable and reducing smoke harshness. The World Health Organization (WHO) considers smoking as a pediatric disease because $90 \%$ of smokers start before the age of 19 and the sooner they start using tobacco, the sooner they become dependent, generating treatment costs for tobaccorelated diseases estimated to reach 21 billion dollars per year in Brazil. Prohibit additives is an important public health measure, in line with Articles 9 \&10 and Partial Guidelines for Implementation of the WHO Framework Convention for Tobacco Control (FCTC) ratified by Brazil in 2005, that addresses content regulation and disclosure of tobacco products, respectively. The present study reviews the regulatory process in the country going through the main events that evolved to RDC14/2012 and prevented its implementation, suggesting a direct interference of the tobacco industry and interest groups in the decision making and entering into force of the regulation. Despite the efforts of ANVISA and favorable legal opinions from the Attorney General's and Federal Prosecutor Offices regarding the constitutionality of the measure, the tobacco industry has sought to delay its entry into force, initially expected for September/2013, but still pending before the Supreme Federal Court in March 2014.

Key-words: tobacco; product regulation; ban of additives and flavors. 


\section{Introdução}

O tabagismo causa cerca de 6 milhões de mortes a cada ano e é a principal causa de morte prematura evitável no mundo, segundo a Organização Mundial da Saúde OMS. Estudos monstram que o fumante que para de fumar na meia idade ganha cerca de dez anos de vida. Estima-se que existem no mundo mais de um bilhão de fumantes, sendo que $80 \%$ vivem em países de baixa ou média renda (OMS, 2013).

Com base em evidências científicas e por meio de firmes decisões políticas, há quase três décadas o Brasil vem implementando um conjunto de medidas de controle do tabaco efetivas e abrangentes. Entre essas políticas destacam-se: a proibição da publicidade de produtos derivados de tabaco, a obrigatoriedade de impressão de imagens e frases de advertência sobre os malefícios para a saúde nas embalagens dos produtos, a proibição de descritores enganosos como light/ultralight nas embalagens dos produtos, a proibição de venda a menores de 18 anos, a proibição do uso de tabaco em ambientes fechados, a obrigatoriedade da impressão do número do telefone do serviço de parar de fumar do Disque Saúde nas embalagens dos produtos derivados do tabaco, a oferta de tratamento para a cessação do tabagismo na rede pública de saúde, o Sistema Único de Saúde (SUS), e o aumento de impostos sobre produtos derivados de tabaco (Szklo et. al., 2012).

Essas medidas fazem parte das obrigações legais do Brasil como EstadoParte da Convenção Quadro para o Controle do Tabaco da Organização Mundial da Saúde (CQCT-OMS) (Brasil, 2006). O estabelecimento da Comissão Nacional para de Negociação e a seguir de Implementação da Convenção-Quadro para o Controle do Tabaco da OMS (CONICQ), respectivamente em 1999 e em 2003 foi uma importante estratégia para o posicionamento do país e do acompanhamento do cumprimento da CQCT/OMS (Romero \& Costa e Silva, 2011).

A adequação dessas políticas com forte impacto na redução da prevalência tem sido observada em alguns estudos. Monteiro e cols. (2007), estimam que o percentual de fumantes adultos (18 anos ou mais) na população brasileira diminuiu 63\% entre 1989 e 2003. Szklo et al. (2012) e Levy e cols. (2012) mostraram um declínio de $41 \%$ de 1989 a 2008 na população de 15 anos ou mais. Segundo dados do Inquérito telefônico realizado pelo Ministério da Saúde através da Secretaria de Vigilância em Saúde sobre fatores de risco para doenças crônicas (VIGITEL), a frequência de fumantes no conjunto das capitais brasileiras vem declinando e, em 
2011, chegou a $14,8 \%$, sendo maior entre os homens $(18,1 \%)$ do que entre as mulheres (12\%) (Brasil, 2012). Schmidt e cols. (2011), ao verificarem o declínio de $20 \%$ na mortalidade por doenças respiratórias crônicas e cardiovasculares no país, atribuiram essa redução à bem sucedida implementação de políticas públicas de saúde, principalmente as que estimulam a redução do consumo de derivados do tabaco e a ampliação de acesso a serviços da atenção básica em saúde.

Apesar desses resultados positivos, a iniciação do tabagismo entre adolescentes e adultos jovens ainda se mostra preocupante. Segundo dados da Pesquisa Nacional de Saúde do Escolar (PENSE), realizada pelo Instituto Brasileiro de Geografia e Estatística (IBGE) como parte da vigilância de doenças e agravos não transmissíveis do Ministério da Saúde em 2009 e 2012, entre mais de 600.000 escolares das capitais brasileiras e, mais recentemente, incluindo municípios menores, cerca de $22 \%$ dos adolescentes de 13 a 15 anos das capitais do país experimentaram fumar e $6 \%$ fumaram nos últimos 30 dias. A comparação dos resultados entre 2009 e 2012 não indica uma redução considerável nesses três anos (IBGE, 2009).

A adição de sabores e aromas aos cigarros tem sido considerada como uma resposta da indústria do fumo visando, entre outros objetivos, reagir às iniciativas governamentais e não governamentais que levam à redução da prevalência do tabagismo, como tem ocorrido no Brasil (ACTBr, 2010).

Aditivos são quaisquer substâncias adicionadas ao fumo, ao papel e/ou ao filtro, durante ou ao final do processamento do cigarro ou do tabaco, que têm o objetivo de conferir sabor e aroma característico da marca. A maioria desses ingredientes (como cacau e açúcar) é adicionada para melhorar o aroma, o sabor e a sensação de irritação causada pela fumaça do cigarro, ou para reduzir o amargor e aspereza decorrentes dos diferentes tipos de fumo utilizados em sua produção. Outros (como os umectantes) são usados para facilitar o processamento do tabaco ou a fabricação do cigarro preservando seus níveis de umidade, mantendo as características originais, incluindo o sabor ao longo do tempo (Brunnemann, 1996).

Os aditivos podem ser artificiais ou naturais e podem ser acrescidos aos produtos derivados de tabaco para recompor as características originais, considerando que vários componentes são perdidos durante o processo de secagem em estufas ou ao ar livre como, por exemplo, os açucares (Chiapetta, 2013). 
O sabor desagradável e o $\mathrm{pH}$ da fumaça do tabaco funcionam como agentes dificultadores da iniciação de jovens no tabagismo. Quanto mais cedo os jovens começam a fumar mais dificuldades terão em parar na idade adulta (Andrade, 2006).

A análise de documentos internos de companhias de tabaco ${ }^{1}$ mostra que, até a década de 1970, os aditivos eram pouco empregados em cigarros, mas que, a partir de 1990, a variedade e o percentual de aditivos em cigarros aumentaram, podendo corresponder em até $10 \%$ do peso na sua composição (ACTBr, 2012).

Com o objetivo de reduzir ainda mais o consumo de derivados de tabaco, principalmente a experimentação entre jovens, a Agência Nacional de Vigilância Sanitária (ANVISA) publicou, em março de 2012, a Resolução da Diretoria Colegiada (RDC) $n^{\circ} 14$, de 2012, proibindo o uso de aditivos que conferem aroma e sabor a esses produtos, como mentol, chocolate, baunilha, caramelo e cravo, entre outros. A adição de açúcar continua permitida. A medida também impede a importação de produtos com esses aditivos. Os fabricantes teriam até 18 meses, a partir da publicação da norma, para retirar do mercado nacional todos os cigarros com sabor (ANVISA, 2012). Apesar dos evidentes benefícios que esta regulação trará para a saúde da população brasileira, em especial das futuras gerações, a medida tem sofrido inúmeros questionamentos na justiça por parte da indústria fumageira e de seus aliados.

O objetivo deste artigo é relatar o processo de proibição dos aditivos dos produtos derivados do tabaco no Brasil, as evidências científicas e os dados epidemiológicos que deram suporte a essa política, e reportar as resoluções da Anvisa sobre o tema até a presente data, além das reações do governo, da indústria fumageira, de grupos de interesse e da sociedade civil ao processo através das informações veiculadas pela mídia.

\section{A regulamentação dos produtos derivados do tabaco e o papel da Anvisa}

O Brasil vem abordando o controle do tabagismo como uma prioridade desde a Constituição Federal de 1988 que, no $4^{\circ}$. parágrafo do art. 220, determina que "a propaganda comercial de tabaco, bebidas alcoólicas, agrotóxicos, medicamentos e terapias estará sujeita a restrições legais e conterá, sempre que necessário, advertência sobre os malefícios decorrentes de seu uso" (Brasil, 1988).

\footnotetext{
${ }^{1}$ Estes documentos são depositados em juízo como fruto do acordo feito na ação coletiva de um grupo de estados americano contra as indústrias de tabaco que comercializam seus produtos naquele país e estão disponíveis em uma biblioteca da Universidade da Califórnia em São Francisco em sua grande maioria no site http://legacy.library.ucsf.edu
} 
O Código Defesa do Consumidor, de 1990, proíbe a publicidade enganosa, capaz de induzir a erro, ainda que por omissão, e que possa induzir o consumidor a se comportar de forma prejudicial ou perigosa à sua saúde ou segurança, além de proibir a venda casada de produtos (Brasil, 1990).

A Lei $n^{\circ}$. 9.294, de 1996, a primeira que regula de forma abrangente o consumo de tabaco no Brasil, dispõe sobre as restrições ao uso e a proibição à propaganda, promoção e patrocínio de produtos fumígeros, abrindo exceção na parte interna dos pontos de venda além de regulamentar as advertências sanitárias nas embalagens desses produtos (Brasil, 1996)

Foi nesse cenário legislativo que a Anvisa foi criada (Brasil, 1999), trazendo uma nova perspectiva para a regulamentação dos derivados de tabaco no Brasil, uma vez que, entre suas competências legais, está a promoção e a proteção da saúde da população, atribuições bem definidas nos artigos $6^{\circ}, 7^{\circ}$ e $8^{\circ}$ da Lei $n^{\circ} .9782$, de 1999 , sendo que 0 artigo $8^{\circ}$ "incumbe à Agência respeitar a legislação em vigor, regulamentar, controlar e fiscalizar produtos e serviços que envolvam risco à saúde pública". O ítem $\mathrm{X}$ do parágrafo $1^{\circ}$ inclui entre os "bens e produtos submetidos ao controle e fiscalização sanitária pela Agência" os "cigarros, cigarrilha, charutos e qualquer outro produto fumígero,derivado ou não do tabaco".

Como uma das medidas da agência recém criada, ela passa a cadastrar e estabelecer o recolhimento de taxas dos produtos por fabricantes e importadores através da Resolução da Diretoria Colegiada (RDC) 320/1999, a regulamentar as informações que devem estar contidas nas embalagens dos "produtos fumígeros" comercializados bem como dos conteúdos de produtos do tabaco de relevância para a saúde pública no país, com base na Lei n 9294, de 1996 e através da RDC 104/2001. A RDC 46/2001, estabelece teores máximos de alcatrão, nicotina e monóxido de carbono, além de proibir o uso de descritores enganosos (como light e mild) (ANVISA, 2001). A RDC 105/2001 inaugura a obrigatoriedade de informação sobre aditivos usados na composição de produtos do tabaco.

Para implementar tais ações, em agosto de 2002 foi criada a Gerência de Produtos Derivados de Tabaco (GGPDT) que recentemente passou a ser denominada Gerência Geral de Produtos Derivados de Tabaco (GGDTA). Suas atribuições incluem: propor normas e procedimentos para o registro cadastral de produtos derivados do tabaco; estabelecer normas e padrões para a produção e comercialização e produtos derivados do tabaco; avaliar, o controle, a fiscalização e a 
avaliação da propaganda dos produtos derivados do tabaco com base na legislação em vigor; estabelecer outros mecanismos de controle e avaliação com vistas à redução do consumo de tabaco, incluindo o processo de articulação com outras instituições, nacionais e internacionais, envolvidas no controle do tabagismo, visando o aprimoramento do desempenho das ações de vigilância sanitária; coordenar as atividades de apuração das infrações à legislação sanitária, instaurar e julgar processo administrativo no âmbito de sua competência; acompanhar e avaliar convênios e contratos com instituições de âmbito nacional visando implementar e contribuir para o fomento da pesquisa científica relativa aos produtos derivados do tabaco; implementar e acompanhar o processo de descentralização nos níveis estadual, municipal e do Distrito Federal, estabelecendo mecanismos para o exercício da fiscalização das normas e padrões de interesse sanitário, respeitando a legislação vigente relativa aos produtos derivados do tabaco (ANVISA, 2013).

As atividades da GGDTA são exercidas em cooperação técnica com o Instituto Nacional do Câncer, do Ministério da Saúde (INCA/MS), com outros órgãos governamentais nacionais e internacionais e com organizações supranacionais, em conformidade com o disposto na CQCT da OMS, ratificada pelo Brasil em 25 de novembro de 2005, por meio do Decreto $n^{0 .}$ 5.658, de 2006 (Brasil, 2006).

Em nível internacional, em fevereiro de 2006, na Primeira Conferência das Partes (COP1), foram adotadas as bases para a elaboração de Guias dos artigos 8 e 9 do Tratado. Em sequência, se estabelece o Grupo de Trabalho para elaboração das Guias de Implementação dos artigos 9 e 10, sendo o Brasil, um dos seus facilitadores, o que pode ter reforçado o papel interno da ANVISA no controle do tabaco (OMS, 2006).

Mais de quatro anos depois, em novembro de 2010, a COP4 aprova as Guias Parcias de Implementação dos artigos 9 e 10, da CQCT da OMS (OMS, 2010), que oferecem a sustentação e o momento político ideal para que a GGDTA apresentasse à Diretoria Colegiada da Anvisa (DICOL) o projeto de proibição de aditivos, recomendado nas Guias (OMS, 2010; ACTBr, 2010).

No mesmo mês, a DICOL estabelece uma Consulta Pública, de número112, de 29/11/2010 (CP12) (ANVISA, 2010) e, propõe prazo para o recebimento de críticas e sugestões relativas à proposta de Revisão da RDC n 46, de 2001 , sobre os teores de alcatrão, nicotina e monóxido de carbono nos cigarros e a proibição de aditivos nos produtos derivados do tabaco, em especial o uso de especiarias e aditivos que 
conferem aroma e sabor. Esta proposta gerou reação imediata do setor produtivo e também da Câmara Setorial do Fumo, vinculada ao Ministério da Agricultura, Pecuária e Abastecimento (esta Câmara Setorial congrega representantes do agronegócio do tabaco no Brasil e foi criada em 2003). O Ministério da Indústria e Comércio também criou uma Câmara da Cadeia Produtiva do tabaco nos mesmos moldes em 2009. Esta reação pode ser observada nos dois eventos que se seguiram: 1. Um dia depois da abertura da CP112, entrou em tramitação na Câmara dos Deputados o Projeto de Lei $n^{\circ}$ 3034, de 2010, do Deputado Luis Heinze (Brasil, 2010), que propõe a suspensão dos efeitos da referida consulta pública da Anvisa.

2. Em abril de 2011, a imprensa divulgou amplamente o estudo encomendado pela indústria fumageira e grupos de interesse à Empresa FVG-Projetos sob o título "Efeitos Socioeconômicos da Regulamentação da Anvisa", sobre os potenciais efeitos das Consultas Públicas nos 112 e 117, de 2010 (FGV-Projetos, 2010). No estudo são apresentadas as principais preocupações do setor no âmbito socioeconômico. Análise do estudo realizada pela Organização Panamericana da Saúde em parceria com a Aliança para o Controle do Tabagismo no Brasil, a Tobacco Free Kids e a Johns Hopkins Bloomberg School of Public Health, concluiu que a publicação havia sido baseada em meras hipóteses sem apresentação dos métodos e materiais usados no estudo, considerando sua divulgação um equívoco (OPAS, 2010). Um dos pontos importantes desta análise é a de que ao contrário da conclusão do estudo da FGV-Projetos, que preconiza que o setor fumageiro é uma fonte geradora de recursos, verfica-se que, em verdade, esse setor mina os recursos do país ao oferecer à população brasileira um produto nocivo para a saúde cujo consumo gera três vezes mais gastos com assistência médica do que contribui com a arrecadação de impostos.

Esta estimativa se baseia no fato de que o custo de doenças tabacorelacionadas para o sistema de saúde no Brasil é de aproximadamente 21 bilhões de reais por ano, considerando apenas os custos das dez principais doenças tabacorelacionadas e sem contar os custos indiretos com tabagismo passivo (Pinto e Ugá, 2010). Como base de comparação, em 2011 a Receita Federal arrecadou com tabaco cerca de 6,3 bilhões de reais em impostos federais, ou seja, menos de um terço dos gastos do governo com saúde.

Em movimento fortemente contrário à CP112, a indústria e seus aliados convocaram seus associados para responderem em massa à consulta com o objetivo 
de fazer pressão contrária à proibição de aditivos, processo esse que resultou no envio de 127.905 participações por via postal, sendo que, de acordo com a Anvisa, poucas eram as cartas que continham contribuições de fato. De qualquer forma, a estratégia retardou o processo de análise da Agência (ABRESI, 2009; ABRASEL-SC, 2011; Molina, 2011; ANVISA, 2011; INCA, 2011).

No decorrer da CP112, a indústria fumageira solicitou que o açúcar contido nas folhas antes da sua cura pudesse ser reintroduzido no processamento do fumo, para repor as perdas, o que aparentemente foi aceito pela Agência (ACTBr, 2012) .

A Associação Brasileira da Indústria do Fumo (ABIFUMO) também usou o estudo citado para justificar a solicitação à Anvisa de extender o prazo de adaptação à futura RDC (que seria adotada um ano depois), para mais dezoito meses a contar da data de sua publicação no Diário Oficial (ANVISA, 2013).

Com o intuito de ampliar a discussão do tema, a Anvisa convocou uma audiência pública para outubro de 2011, no Rio de Janeiro, que teve sua suspensão decretada pela Justiça a pedido do Sindicato Interestadual das Indústrias do Tabaco, sob a alegação de falta de espaço no local designado para comportar um suposto grande número de participantes interessados (ANVISA, 2011). A audiência pública aconteceu, por fim, em Brasília, no dia 6 de dezembro de 2011, num ginásio de esportes, em atenção à demanda judicial, e contou com a participação de plantadores de tabaco, convocados por grupos de interesse, para fazer pressão contra a RDC 14 (AFUBRA, 2011).

Nesse mesmo período, entrou em discussão no Congresso Nacional a Medida Provisória $n^{\circ} 540$, de 2011, que propunha, além de uma outra extensa pauta de medidas, a alteração do regime de tributação do Imposto sobre Produtos Industrializados (IPI) dos cigarros, dando competência ao Poder Executivo para fixar o preço mínimo do produto no varejo. Na prática, a intenção do governo era elevar os impostos dos cigarros para aumentar a arrecadação e, também, reduzir o estímulo ao consumo do produto.

Inesperadamente, o relator da matéria apresentou uma série de emendas que não faziam parte da medida original. Estas emendas visavam modificar as restrições ao fumo vigentes (Partido Progressista, 2011), entre as quais um artigo que autorizava o uso de aditivos químicos (mentol e cravo) nos cigarros brasileiros. Se aprovadas estas medidas, todo o processo de consulta que estava sendo conduzido pela Anvisa seria esvaziado. 
Após forte reação da sociedade civil, da mídia e dos setores do governo comprometidos com a saúde pública, o tema foi retirado do texto final e o resultante projeto de lei de conversão tributária (PLV n 29, de 2011) foi aprovado no Senado, dando origem à Lei $n^{\circ} 12.546$, de 14 de dezembro de 2011, que, ao rejeitar as emendas propostas, acabou por referendar avanços no controle do tabagismo ao estender a proibição da publicidade também aos pontos de venda e tornar o Brasil o maior país do mundo a legislar sobre ambientes fechados totalmente livres de fumo.

Em nova investida contra a proposta da CP112, nessa mesma época, foi submetido à Câmara dos Deputados, o Projeto de Lei n 2901, de 2011, do Deputado Jerônimo Goergen (PP-RS), que proíbia o uso de aditivos em produtos fumígeros, derivados ou não do tabaco. Este projeto no entanto abria exceção ao tabaco e ao mentol, acrescentando um artigo à lei nº 9.294, de 1996. (Brasil, 2011).

Mesmo com toda a oposição da indústria fumageira e seus aliados e graças ao debate social que apoiou a medida, a Anvisa publicou, em 15 de março de 2012, a Resolução da Diretoria Colegiada no 14, de 2012 (ANVISA, 2012), proibindo o uso de aditivos nos cigarros, incluindo substâncias sintéticas e naturais em qualquer forma de apresentação, com propriedades flavorizantes ou aromatizantes que possam conferir, intensificar, modificar ou realçar sabor ou aroma do produto, incluindo os aditivos identificados como flavorizantes ou aromatizantes. A decisão foi apoiada por ampla divulgação na mídia e teve, como suporte, estudo da Escola Nacional de Saúde Pública (ENSP), em parceria com a Universidade Federal do Rio de Janeiro (UFRJ) e o Instituto Nacional de Câncer (INCA).

Este estudo, realizado com 17.127 escolares de 13 a 15 anos em dez cidades brasileiras, entre 2005 e 2009, mostrou que, dos 5.700 alunos entrevistados que experimentaram fumar, $54 \%$ preferiam cigarros com sabor, sendo de $38 \%$ a preferência por cigarros mentolados e de $16 \%$ por outros sabores como chocolate, morango, cravo etc. Jovens que fumaram cigarros com sabor apresentaram maior percentual de comportamento de risco para o estabelecimento da dependência da nicotina, como fumar maior número de cigarros e em maior número de dias, em comparação com aqueles que preferem cigarros sem sabor. O estudo mostrou também que o uso de cigarros com sabor entre jovens no Brasil é elevado quando comparado a outros países (Figueiredo et al., 2012).

Este estudo reforça o grande mérito da RDC $n^{0} 14$, de 2012, que foi o de regulamentar uma medida que será efetiva para a redução da iniciação ao tabagismo 
de crianças e jovens, já que, ao aumentar a palatividade e potencializar a ação da nicotina, os aditivos funcionam como atrativos para a experimentação de cigarros e outros produtos do tabaco e aumentam o risco de dependência. A entrada em vigor da RDC 14/12 estava prevista para 13 de setembro de 2013. Mas, o processo estava longe do fim.

Em paralelo ao que foi descrito, ações no Judiciário foram encaminhadas, para que a proibição de aditivos nos produtos do tabaco não fosse efetivada no Brasil. Surpreendentemente também, o papel da ANVISA passou a ser questionado. Em novembro de 2012, a Confederação Nacional da Indústria (CNI) ajuizou uma ação direta de inconstitucionalidade (ADI 4874/2012) no Superior Tribunal Federal (STF) pedindo a inconstitucionalidade de parte da lei que criou a Anvisa e, consequentemente, da resolução que proíbe a comercialização de cigarros com aromas e sabores (Migalhas, 2012; Brasil, 2013). Este processo levou a Advocacia Geral da União (AGU) e a Procuradoria Geral da República a apresentarem pareceres em defesa da constitucionalidade do mandato da Anvisa, dando suporte à proibição dos aditivos nos produtos fumigenos previstos na RDC 14/2012 (Wilton Castro, 2013).

Adicionalmente, a indústria do tabaco continuou no seu intuito de tentar anular os efeitos da RDC14/2012, ajuizando no Tribunal Regional Federal da Bahia, uma ação coletiva declaratória de nulidade de ato administrativo movida pelo Sindicato Interestadual da Indústria do Tabaco (SindiTabaco), que ainda aguarda julgamento; em sequência, por meio de liminar concedida pela Justiça ao Sinditabaco-DF, em ação ordinária coletiva apresentada na $9^{a}$ Vara da Justiça Federal do Distrito Federal, os setores interessados conseguiram suspender os efeitos da RDC 14/2012 (Brasil, 2012).

Como parte da estratégia para impedir a proibição de aditivos em seus produtos, alegando que isto teria impacto na cadeia produtiva, em especial para os plantadores do fumo, produtores e varejistas, e estimularia o comércio ilícito, a indústria fumageira continuou a pressionar o Poder Judiciário para que os aditivos voltassem a ser liberados ou, no caso da liberação não ser possível, para que a lista dos aditivos proibidos fosse reduzida (Castro \& Costa e Silva, 2013).

O setor regulado encaminhou à ANVISA um questionamento para que aditivos específicos fossem autorizados no país (ANVISA, 2013). Como resultado da avaliação ao pleito da indústria e debaixo de forte pressão de interesses econômicos 
contrários à RDC14/2012, a Anvisa publicou a Instrução Normativa $\mathrm{n}^{\circ}$ 6, de 26/08/2013, liberando provisoriamente 121 aditivos de produtos fumígeros por um período de doze meses, até que seja feita sua análise em oito meses por grupo de especialistas (ANVISA, 2013) definidos na Portaria 1980/2013.

As principais medidas relacionadas à proibição de aditivos em produtos do tabaco no Brasil, as reações do setor produtivo e dos grupos de interesse e os encaminhamentos dados até o princípio de 2014 estão sumarizados no Quadro 1.

Quadro 1: Medidas selecionadas que tem relação ou são destinadas à regulamentação dos produtos do tabaco no Brasil com ênfase nos seus conteúdos, em especial os aditivos

\begin{tabular}{|l|l|l|l|}
\hline \multicolumn{1}{|c|}{ Fato } & $\begin{array}{c}\text { Data/ } \\
\text { Período }\end{array}$ & \multicolumn{1}{c|}{ Consequência } & \multicolumn{1}{c|}{ Conteúdo/Encaminhamento } \\
\hline $\begin{array}{l}\text { A Agência Nacional } \\
\text { de Vigilância } \\
\text { Sanitária (Anvisa) é } \\
\text { criada pela Lei no } \\
9782 / 1999\end{array}$ & $26 / 01 / 1999$ & $\begin{array}{l}\text { Cria a Anvisa e } \\
\text { define o Sistema } \\
\text { Nacional de } \\
\text { Vigilância Sanitária }\end{array}$ & $\begin{array}{l}\text { Regulamenta, controla e fiscaliza } \\
\text { produtos que envolvam risco à saúde } \\
\text { considerando bens, e produtos } \\
\text { submetidos à esta fiscalização } \\
\text { cigarros, cigarrilhas, charutos e } \\
\text { qualquer outro produto fumígero } \\
\text { derivado ou não do tabaco }\end{array}$ \\
\hline $\begin{array}{l}\text { Anvisa publica a } \\
\text { RDC 320/1999 }\end{array}$ & $21 / 07 / 1999$ & $\begin{array}{l}\text { Dispõe sobre o } \\
\text { cadastro de produtos } \\
\text { do tabaco e } \\
\text { estabelece } \\
\text { recolhimento de } \\
\text { taxas por marca }\end{array}$ & $\begin{array}{l}\text { A medida inaugura a obrigatoriedade } \\
\text { do cadastro de produtos a } \\
\text { fabricantes e importadores e pede } \\
\text { informações de dados de venda e } \\
\text { composição do produto e } \\
\text { componentes e de compostos } \\
\text { presentes na corrente primária da } \\
\text { fumaça do tabaco }\end{array}$ \\
\hline $\begin{array}{l}\text { Anvisa publica a } \\
\text { RDC 46/2001 }\end{array}$ & $28 / 03 / 2001$ & $\begin{array}{l}\text { Estabelece os teores } \\
\text { máximos de alcatrão, } \\
\text { nicotina e monóxido } \\
\text { de carbono }\end{array}$ & $\begin{array}{l}\text { A RDC 46/2001 inaugura o grupo de } \\
\text { resoluções que visam regulamentar } \\
\text { conteúdos e teores de produtos do } \\
\text { tabaco e se torna o primeiro país no } \\
\text { mundo a proibir descritores } \\
\text { enganosos como light e mild }\end{array}$ \\
\hline $\begin{array}{l}\text { Anvisa publica a } \\
\text { RDC 104/2001, }\end{array}$ & $31 / 05 / 2001$ & $\begin{array}{l}\text { Determina a inserção } \\
\text { de imagens nas } \\
\text { embalagens de } \\
\text { produtos do tabaco, }\end{array}$ & $\begin{array}{l}\text { A RDC 104/2001 torna o Brasil o } \\
\text { segundo país no mundo a dispor de } \\
\text { advertências sanitárias com imagens }\end{array}$ \\
\hline $\begin{array}{l}\text { Anvispo publica a } \\
\text { RDC 105/2001 } \\
\text { cadastro de produtos } \\
\text { do tabaco }\end{array}$ & $\begin{array}{l}\text { A RDC acrescenta novas exigências } \\
\text { à RDC 320/1999 incluindo produtos } \\
\text { não fumígenos e inaugura a } \\
\text { obrigatoriedade de informação sobre } \\
\text { aditivos usados na composição de } \\
\text { produtos do tabaco }\end{array}$ \\
\hline
\end{tabular}




\begin{tabular}{|c|c|c|c|}
\hline Fato & $\begin{array}{c}\text { Datal } \\
\text { Período }\end{array}$ & Consequência & Conteúdo/Encaminhamento \\
\hline $\begin{array}{l}\text { Anvisa estabelece a } \\
\text { Gerência de } \\
\text { Produtos Derivados } \\
\text { do Tabaco (GPDTA) } \\
\text { por meio da Portaria } \\
\text { 435/2002. }\end{array}$ & $01 / 08 / 2002$ & $\begin{array}{l}\text { Cria e define } \\
\text { competências }\end{array}$ & $\begin{array}{l}\text { Entre as atividades previstas, a } \\
\text { GPDTA estabelece normas e } \\
\text { procedimentos para registro dos } \\
\text { dados cadastrais e normas e } \\
\text { padrões, para a produção e } \\
\text { comercialização, fiscaliza a } \\
\text { propaganda e o uso do tabaco em } \\
\text { ambientes coletivos. A GPDTA } \\
\text { mudou sua denominação em } 2013 \\
\text { para GGDTA }\end{array}$ \\
\hline $\begin{array}{l}\text { Governo Brasileiro } \\
\text { cria a Comissão } \\
\text { Nacional de } \\
\text { Implementação da } \\
\text { Convenção-Quadro } \\
\text { para o Controle do } \\
\text { Tabaco (CONICQ) } \\
\text { através do Decreto } \\
01 / 08 / 2003\end{array}$ & $01 / 08 / 2003$ & $\begin{array}{l}\text { Articular e organizar } \\
\text { a implementação de } \\
\text { uma agenda } \\
\text { governamental } \\
\text { intersetorial para o } \\
\text { cumprimento das } \\
\text { obrigações da } \\
\text { CQCT. A CONICQ } \\
\text { foi precedida pela } \\
\text { Comissão Nacional } \\
\text { para a Negociação } \\
\text { da CQCT, criada } \\
\text { pelo Decreto } n^{\circ} \\
\text { 3.136/1999 }\end{array}$ & $\begin{array}{l}\text { O Brasil estabelece uma comissão } \\
\text { interministerial que aborda uma } \\
\text { agenda comum de implementação } \\
\text { da CQCT da OMS no pais incluindo } \\
\text { membros que abordam a relevância } \\
\text { da economia do tabaco (MAPA e } \\
\text { MEDIC) mas protegendo esta } \\
\text { agenda da influência indevida da } \\
\text { indústria fumageira }\end{array}$ \\
\hline $\begin{array}{l}\text { O Ministério da } \\
\text { Agricutura, Pecuária } \\
\text { e Abastecimento } \\
\text { (MAPA) cria a } \\
\text { Câmara Setorial da } \\
\text { Cadeia Produtiva do } \\
\text { Fumo através da } \\
\text { Portaria 231/2004 }\end{array}$ & $10 / 09 / 2004$ & $\begin{array}{l}\text { A Portaria cria a } \\
\text { câmara e designa os } \\
\text { membros para } \\
\text { comporem a Câmara }\end{array}$ & $\begin{array}{l}\text { A criação da Câmara Setorial do } \\
\text { Fumo no MAPA oficializa a } \\
\text { representação e influência da } \\
\text { indústria fumageira dentro do } \\
\text { governo brasileiro legitimando sua } \\
\text { interferência na implementação da } \\
\text { CQCT da OMS pelo país, entre elas, } \\
\text { a oposição à regulação dos aditivos }\end{array}$ \\
\hline $\begin{array}{l}\text { Brasil se torna } \\
\text { Estado-Parte da } \\
\text { Convenção-Quadro } \\
\text { para o Controle do } \\
\text { Tabaco da OMS } \\
\text { (CQCT) através do } \\
\text { Decreto 5658/2006 }\end{array}$ & $02 / 01 / 2006$ & $\begin{array}{l}\text { O Brasil se torna } \\
\text { Parte legalmente } \\
\text { vinculada ao tratado, } \\
\text { devendo cumprir } \\
\text { integralmente seus } \\
\text { artigos e observar } \\
\text { suas guias de } \\
\text { implementação }\end{array}$ & $\begin{array}{l}\text { Os artigos } 9 \text { e } 10 \text { da CQCT da OMS } \\
\text { versam sobre a regulamentação do } \\
\text { conteúdo e divulgação das } \\
\text { informações dos produtos derivados } \\
\text { do tabaco respectivamente, tornando } \\
\text { o Brasil legalmente vinculado ao seu } \\
\text { cumprimento }\end{array}$ \\
\hline $\begin{array}{l}\text { O Ministério do } \\
\text { Desenvolvimento, } \\
\text { Indústria e Comércio } \\
\text { Exterior (MEDIC) cria } \\
\text { a Câmara Setorial da } \\
\text { Cadeia Produtiva de } \\
\text { Tabaco através da } \\
\text { Portaria 60/2009 }\end{array}$ & $03 / 02 / 2009$ & $\begin{array}{l}\text { A Câmara tem por } \\
\text { finalidade propor, } \\
\text { apoiar e acompanhar } \\
\text { ações para o } \\
\text { desenvolvimento das } \\
\text { atividades das } \\
\text { cadeias produtivas } \\
\text { do agronegócio } \\
\text { brasileiro. }\end{array}$ & $\begin{array}{l}\text { A criação da Câmara Setorial do } \\
\text { Fumo no MEDIC reforça a } \\
\text { representação e influência da } \\
\text { indústria fumageira dentro do } \\
\text { governo brasileiro em oposição à } \\
\text { implementação das diretrizes do } \\
\text { artigo } 5.3 \text { da CQCT da OMS }\end{array}$ \\
\hline
\end{tabular}




\begin{tabular}{|c|c|c|c|}
\hline Fato & $\begin{array}{c}\text { Datal } \\
\text { Período }\end{array}$ & Consequência & Conteúdo/Encaminhamento \\
\hline $\begin{array}{l}\text { Aprovação das guias } \\
\text { parciais dos artigos } 9 \\
\text { e } 10 \text { na VI } \\
\text { Conferência das } \\
\text { Partes, no Uruguai } \\
\text { (COP4) }\end{array}$ & $20 / 11 / 2010$ & $\begin{array}{l}\text { Grande pressão } \\
\text { contrária da indústria } \\
\text { do tabaco; Câmara } \\
\text { Setorial do Fumo do } \\
\text { Ministério da } \\
\text { Agricultura se } \\
\text { posiciona } \\
\text { oficialmente de } \\
\text { forma contrária à } \\
\text { aprovação das guias. }\end{array}$ & $\begin{array}{l}\text { As guias legitimam a proposta do } \\
\text { Brasil, como Estado-Parte, de } \\
\text { regulamentar a proibição de aditivos } \\
\text { em produtos do tabaco através de } \\
\text { encaminhamento de projeto } \\
\text { preparado pela Anvisa/GGDTA para } \\
\text { a Diretoria Colegiada da Anvisa } \\
\text { (DICOL) }\end{array}$ \\
\hline $\begin{array}{l}\text { DICOL decide abrir } \\
\text { Consulta Pública da } \\
\text { Anvisa } \mathrm{n}^{\circ} 112\end{array}$ & $29 / 11 / 2010$ & $\begin{array}{l}\text { Abertura para que os } \\
\text { setores interessados } \\
\text { e a sociedade } \\
\text { opinem sobre a } \\
\text { proibição dos } \\
\text { aditivos nos produtos } \\
\text { do tabaco e dá } \\
\text { outras providências }\end{array}$ & $\begin{array}{l}\text { Prazo dado para críticas e sugestões } \\
\text { relativas à proposta de revisão da } \\
\text { RDC } 46 / 2001 \text { incluindo a proibição } \\
\text { de aditivos nos produtos derivados } \\
\text { do tabaco é aberto de } 29 \text { de } \\
\text { novembro de } 2010 \text { - } 31 \text { de março de } \\
2011 \text {. }\end{array}$ \\
\hline $\begin{array}{l}\text { Projeto de Decreto } \\
\text { Legislativo } n^{\circ} 3034, \\
\text { de } 2010, \text { é } \\
\text { apresentado no } \\
\text { Congresso Nacional. }\end{array}$ & $30 / 11 / 2010$ & $\begin{array}{l}\text { O projeto se opõe à } \\
\text { CP112 buscando } \\
\text { sustar os efeitos da } \\
\text { Consulta Pública da } \\
\text { Anvisa } n^{\circ} 112 \text {, de } 29 \\
\text { de novembro de } \\
2010\end{array}$ & $\begin{array}{l}\text { O projeto segue tramitando na } \\
\text { Câmara dos Deputados após passar } \\
\text { por várias Comissões }\end{array}$ \\
\hline $\begin{array}{l}\text { FGV- Projetos } \\
\text { publica estudos } \\
\text { sobre os Efeitos da } \\
\text { Regulamentação da } \\
\text { Anvisa, } \\
\text { encomendado pela } \\
\text { indústria fumageira e } \\
\text { grupos de interesse } \\
\end{array}$ & 2010 & $\begin{array}{l}\text { Estudo dos Efeitos } \\
\text { Socioeconômicos } \\
\text { dos assuntos de que } \\
\text { tratam as Consultas } \\
\text { Públicas } \mathrm{n}^{\text {os }} .112 \mathrm{e} \\
117 \text { de } 2010 .\end{array}$ & $\begin{array}{l}\text { O estudo é publicado e usado para } \\
\text { subsidiar as justificativas da indústria } \\
\text { fumageira mas é criticado por } \\
\text { entidades nacionais e internacionais } \\
\text { como a OPAS, ACT e Tobacco Free } \\
\text { Kids, pela falta de consistência das } \\
\text { informações. }\end{array}$ \\
\hline $\begin{array}{l}\text { Reação direta da } \\
\text { indústria do tabaco e } \\
\text { grupos de interesse }\end{array}$ & 2011 & $\begin{array}{l}\text { Anúncios veiculados } \\
\text { nos jornais de } \\
\text { grande circulação do } \\
\text { Brasil por grupos de } \\
\text { interesse incluíam } \\
\text { federações e } \\
\text { associações de } \\
\text { fumicultores, } \\
\text { varejistas e do setor } \\
\text { de hospitalidade }\end{array}$ & $\begin{array}{l}\text { Reação à resolução da Diretoria } \\
\text { Colegiada da Anvisa por meio do } \\
\text { envio de } 127.905 \text { participações por } \\
\text { via postal para apreciação do órgão } \\
\text { como resposta à consulta pública } \\
\text { retarda o encaminhamento do } \\
\text { processo. Segundo a Anvisa, apenas } \\
10 \text { continham contribuições reais. }\end{array}$ \\
\hline $\begin{array}{l}\text { Reinvindicação da } \\
\text { indústria para } \\
\text { flexibilização do texto } \\
\text { proposto - } \\
\text { reinserção do açucar }\end{array}$ & 2011 & $\begin{array}{l}\text { Retirada do açúcar } \\
\text { da lista de aditivos } \\
\text { com proposta de } \\
\text { reposição para } \\
\text { compensar as } \\
\text { perdas associadas à } \\
\text { cura da folha (perdas } \\
\text { consideradas } \\
\text { naturais) } \\
\end{array}$ & $\begin{array}{l}\text { Anvisa acomodou a reinvindicação } \\
\text { da indústria fumageira na RDC } \\
14 / 2012\end{array}$ \\
\hline $\begin{array}{l}\text { Primeira Audiência } \\
\text { Pública da ANVISA }\end{array}$ & $06 / 10 / 2011$ & $\begin{array}{l}\text { Marcada no Rio de } \\
\text { Janeiro e adiada na } \\
\text { véspera do dia } \\
\text { marcado }\end{array}$ & $\begin{array}{l}\text { Decisão judicial apresentada pelo } \\
\text { Sindicato Interestadual das } \\
\text { Indústrias do Tabaco alegou falta de } \\
\text { espaço para comportar os } \\
\text { participantes potenciais }\end{array}$ \\
\hline
\end{tabular}




\begin{tabular}{|c|c|c|c|}
\hline Fato & $\begin{array}{c}\text { Datal } \\
\text { Período }\end{array}$ & Consequência & Conteúdo/Encaminhamento \\
\hline $\begin{array}{l}\text { Segunda Audiência } \\
\text { Pública da ANVISA }\end{array}$ & $06 / 12 / 2011$ & $\begin{array}{l}\text { Audiência pública } \\
\text { marcada em Brasília, } \\
\text { no Ginásio Nilson } \\
\text { Nelson. }\end{array}$ & $\begin{array}{l}\text { Participação de representantes da } \\
\text { saúde pública do governo e da } \\
\text { sociedade civil, parlamentares, } \\
\text { plantadores de tabaco e da indústria } \\
\text { para fazer pressão contra a RDC, } \\
\text { sob o argumento de impacto no } \\
\text { desemprego nas regiões } \\
\text { fumicultoras e êxodo rural. }\end{array}$ \\
\hline $\begin{array}{l}\text { Medida Provisoria } \mathrm{n}^{\circ} \text {. } \\
540 / 2011 \text { tramita no } \\
\text { Congresso Nacional }\end{array}$ & $03 / 11 / 2011$ & $\begin{array}{l}\text { Coloca em risco a } \\
\text { proibição dos } \\
\text { aditivos em produtos } \\
\text { do tabaco, por incluir } \\
\text { artigo para autorizar } \\
\text { o uso de aditivos } \\
\text { químicos (mentol e } \\
\text { cravo). }\end{array}$ & $\begin{array}{l}\text { O tema é retirado do texto final e o } \\
\text { PLV } 29 / 2011 \text { é aprovado no Senado } \\
\text { gerando a Lei } n^{\circ} \text {. } 12.546 \text {, de } \\
14 / 12 / 201 \text { que não aborda a questão } \\
\text { dos aditivos. }\end{array}$ \\
\hline $\begin{array}{l}\text { Projeto de Lei } n^{\circ} \\
\text { 2901/11, do } \\
\text { Deputado Jerônimo } \\
\text { Goergen (PP-RS) }\end{array}$ & $08 / 12 / 2011$ & $\begin{array}{l}\text { Proíbe o uso de } \\
\text { aditivos em produtos } \\
\text { fumígeros, derivados } \\
\text { ou não do tabaco, } \\
\text { mas cria exceção ao } \\
\text { tabaco e o mentol. }\end{array}$ & $\begin{array}{l}\text { Apensado ao } \mathrm{PL} 7233 / 2010 \text { e ao } \mathrm{PL} \\
928 / 2003 \text {, que proíbe o uso dos } \\
\text { descritores enganosos em produtos } \\
\text { do tabaco }\end{array}$ \\
\hline RDC 14 /12 Anvisa & $14 / 03 / 2012$ & $\begin{array}{l}\text { Dispõe sobre a } \\
\text { restrição de inclusão } \\
\text { de aditivos em } \\
\text { produtos fumígeros } \\
\text { em geral, derivados } \\
\text { ou não do tabaco, } \\
\text { comercializados no } \\
\text { território nacional. }\end{array}$ & $\begin{array}{l}\text { Grande discussão na mídia, } \\
\text { ENSP/Fiocruz, UFRJ e INCA } \\
\text { publicam estudo sobre o consumo de } \\
\text { cigarros com aditivos por jovens } \\
\text { dando suporte à medida; estratégias } \\
\text { da indústria usam mobilização } \\
\text { pública para questionar o "estado- } \\
\text { babá" e a "liberdade de escolha" }\end{array}$ \\
\hline $\begin{array}{l}\text { Ação Ordinária } \\
\text { Coletiva: 9a Vara da } \\
\text { Justiça Federal do } \\
\text { DF, movida pelo } \\
\text { Sinditabaco. }\end{array}$ & $25 / 09 / 2012$ & $\begin{array}{l}\text { O pedido de liminar } \\
\text { para suspensão dos } \\
\text { efeitos da RDC } \\
14 / 2012 \text { foi deferido } \\
\text { em primeira instância }\end{array}$ & $\begin{array}{l}\text { A Anvisa (por meio da AGU) } \\
\text { apresentou Recurso de Agravo de } \\
\text { Instrumento ao Tribunal Regional } \\
\text { Federal da } 1^{\text {a }} \text { Região, requerendo a } \\
\text { suspensão dos efeitos da liminar } \\
\text { mas o pedido não foi deferido. A } \\
\text { Anvisa apresentou recursos ao STF } \\
\text { e ao STJ, que ainda não foram } \\
\text { apreciados }\end{array}$ \\
\hline $\begin{array}{l}\text { Confederação } \\
\text { Nacional da Indústria } \\
\text { (CNI) ajuiza no STF } \\
\text { uma Ação Direta de } \\
\text { Inconstitucionalidade } \\
\text { (ADI) n. 4874. Amici } \\
\text { curie } 1 \text { admitidos: } \\
\text { Fentifumo; } \\
\text { Sinditabaco-BA; } \\
\text { Amata; ACTBR e } \\
\text { Abifumo }\end{array}$ & $06 / 11 / 2012$ & $\begin{array}{l}\text { Pede a } \\
\text { inconstitucionalidade } \\
\text { de parte da lei que } \\
\text { criou a Anvisa e } \\
\text { consequentemente } \\
\text { da RDC14/2012. }\end{array}$ & $\begin{array}{l}\text { O processo está aguardando pauta } \\
\text { para julgamento em sessão } \\
\text { plenária. Foi incluído na pauta da } \\
\text { sessão do dia } 11 / 09 / 2013 \text {, mas foi } \\
\text { retirado da pauta, em razão da } \\
\text { liminar concedida no processo que } \\
\text { tramita na Justiça Federal do DF, } \\
\text { que suspende os efeitos da } \\
\text { resolução }\end{array}$ \\
\hline $\begin{array}{l}\text { Advocacia Geral da } \\
\text { União e Procuradoria } \\
\text { Geral da República } \\
\text { apresentam } \\
\text { pareceres em defesa } \\
\text { da Anvisa na ADI } \\
4874 / 2012\end{array}$ & $01 / 04 / 2013$ & $\begin{array}{l}\text { Pareceres suportam } \\
\text { restrição ao uso de } \\
\text { aditivos }\end{array}$ & Apresentados ao STF \\
\hline
\end{tabular}




\begin{tabular}{|c|c|c|c|}
\hline Fato & $\begin{array}{c}\text { Datal } \\
\text { Período }\end{array}$ & Consequência & Conteúdo/Encaminhamento \\
\hline $\begin{array}{l}\text { Ação Coletiva } \\
\text { Declaratória de } \\
\text { Nulidade Ato } \\
\text { Administrativo: } 3^{a} \\
\text { Vara da Justiça } \\
\text { Federal da Bahia, } \\
\text { movida pelo } \\
\text { Sinditabaco-BA. }\end{array}$ & $11 / 06 / 2013$ & $\begin{array}{l}\text { TRF1 BA concede } \\
\text { medida antecipatória } \\
\text { ordenando a } \\
\text { suspensão dos } \\
\text { efeitos dos art. } 6^{\circ} \text { e } \\
7^{\circ} \text { da RDC } 14\end{array}$ & $\begin{array}{l}\text { A Anvisa apresentou recurso de } \\
\text { Agravo de Instrumento perante o } \\
\text { Tribunal Regional Federal } 1^{a} \text { Região } \\
\text { e foi revogada a decisão que } \\
\text { concedeu a liminar. O Sinditabaco - } \\
\text { BA recorreu, mas o recurso ainda } \\
\text { não foi julgado. }\end{array}$ \\
\hline $\begin{array}{l}\text { Instrução normativa - } \\
\text { IN06/2013 da Anvisa }\end{array}$ & $27 / 08 / 2013$ & $\begin{array}{l}\text { Libera } \\
\text { provisoriamente } 121 \\
\text { aditivos dos efeitos } \\
\text { da RDC14/2012 }\end{array}$ & $\begin{array}{l}\text { Análise dos } 121 \text { aditivos liberados da } \\
\text { RDC14/2012 será feita no período de } \\
\text { doze meses e é vista como } \\
\text { retrocesso por grupos da sociedade } \\
\text { civil }\end{array}$ \\
\hline $\begin{array}{l}\text { Portaria } 1980 / 2013 \\
\text { institui Grupo de } \\
\text { Trabalho no âmbito } \\
\text { da ANVISA. }\end{array}$ & $\begin{array}{c}24 \text { de } \\
\text { dezembro } \\
\text { de } 2013\end{array}$ & $\begin{array}{l}\text { Grupo criado para } \\
\text { avaliar os aditivos } \\
\text { utilizados nos } \\
\text { produtos derivados } \\
\text { do tabaco listados no } \\
\text { Anexo da Instrução } \\
\text { Normativa-IN no } \\
06 / 2013\end{array}$ & $\begin{array}{l}\text { O grupo de trabalho terá o prazo de } \\
08 \text { (oito) meses para a conclusão } \\
\text { dos trabalhos, contado da data de } \\
\text { publicação desta portaria. }\end{array}$ \\
\hline
\end{tabular}

2 Amici curie admitidos: Federação Nacional dos Trabalhadores da Indústria do Fumo e afins (FENTIFUMO) e Sindicato da Indústria do Tabaco do estado da Bahia (SINDITABACO-BA), Associação Mundial Anti tabagismo (AMATA), Aliança para o Controle do Tabaco (ACTBR) e Associação Brasileira das Indústrias do Fumo (ABIFUMO) recebidas em 13/09/2013

\section{A falácia da argumentação de que os aditivos são quimicamente aceitáveis.}

Analisar a lista de aditivos usados na fabricação de produtos derivados do tabaco é um passeio pelo mundo da química. Nela podem ser adicionadas mais de 130 substâncias individuais e 30 misturas quimicamente indefinidas que incluem precursores de substâncias cancerígenas, tais como aminoácidos, metilonaftilcetonas, cloreto de amônio, nitratos, glicóis e polissacarídeos (Bornhauser e cols, 2006).

O argumento da indústria fumageira contrária à regulação dos aditivos nos cigarros tem por base o fato de que, na sua maioria, eles são permitidos o uso em alimentos e, consequentemente, são seguros. Mas isto não funciona dessa maneira com produtos submetidos a condições diversas e que além disto são inalados.

Alimentos in natura ou com adição de aditivos (flavorizantes, conservantes, aromatizantes etc.) ao serem expostos à temperatura de cozimento (que pode variar de 65 a 100 graus centrígrados) têm um comportamento diferente do que é encontrado na ponta dos cigarros/charutos/cigarrilhas, que chegam a 600-900 graus centígrados, resultando na formação de dióxido de carbono, óxidos nitrosos, dióxido de enxofre e água por sublimação/evaporação parcial, e da conversão em produtos de pirólise, dentre os quais são encontrados compostos classificados como 
cancerígenos pela Agência Internacional em Pesquisa em Câncer (IARC/OMS, 2004). Assim, não é só a forma original dos aditivos que determina seu potencial tóxico: muito mais relevante são os seus produtos de tranformação por meio do processo denominado pirólise.

Outra diferença decorre do fato de que os aditivos alimentares usados em derivados do tabaco são inalados, e seus efeitos surgirão principalmente no trato respiratório, com uma absorção muito mais rápida e um efeito muito diferente do causado pela ingestão. Uma porção menor do material particulado que sofre pirólise também é engolida, já que se deposita sobre as mucosas e membranas da cavidade oral (OMS, 2010).

Conclui-se que não se pode generalizar a afirmação de que os aditivos adicionados ao tabaco têm o mesmo efeito sobre o organismo que os colocados nos alimentos. Embora a estrutura química de alguns desses compostos seja conhecida, a maioria dos compostos químicos resultantes da pirólise de aditivos é pouco avaliada do ponto de vista toxicológico e de efeitos sobre a saúde humana, devendo ser evitados.

\section{Conclusão}

Os produtos derivados de tabaco e em especial, os cigarros são confeccionados para disponibilizar ao fumante a droga nicotina. Na medida em que o consumidor se acostuma com a irritação inicial causada pela fumaça, fica aprisionado pelos efeitos da droga e submetido a uma gama de substâncias que oferecem danos à saúde. Esse processo é facilitado pelo uso de aditivos que suavizam o sabor da fumaça, tornam o produto mais aceitável, principalmente para os grupos de consumidores mais vulneráveis como crianças e jovens, novos consumidores que entram no mercado diariamente substituindo aqueles que sucumbem em decorrência do tabagismo.

Para proteger estes consumidores é preciso proibir aditivos com sabores característicos como o mentol, cravo, chocolate, ou baunilha. Além disto, é preciso banir todo e qualquer outro aditivo, pois a produção de cigarros saborizados pode ser feita sem se adicionar uma única essência natural mas, a partir de complexas reações químicas cujo resultado final simula os sabores desejados.

Nesse sentido, o governo brasileiro, por meio da atuação da Anvisa, deve continuar sendo uma referência mundial na regulação de produtos derivados de 
tabaco e, assim, continuar a desempenhar seu papel regulador no desenvolvimento de políticas públicas que protejam a saúde das futuras gerações.

$\mathrm{Na}$ tentativa de discutir o impacto econômico que uma medida de proibição de aditivos em produtos do tabaco poderia ter no Brasil, a indústria encomendou estudos cujos argumentos tem consistência científica discutível e que promovem de forma equivocada os interesses econômicos dos grandes produtores, contrariando os interesses da saúde pública. Estes não devem ser considerados para nortear a discussão e eventual decisão sobre medidas reguladoras de produtos do tabaco. Isto é particularmente aplicável ao caso da RDC14/2012, ora sob forte pressão para retrocessos em relação a sua validade, prazos de aplicação e conteúdos, com a judicialização da saúde pública levando apenas à defesa de interesses corporativos, com alegações falaciosas de impactos indesejáveis sobre o setor mais fraco da cadeia produtiva, os plantadores de fumo.

Em decorrência, manter a proibição dos aditivos como um todo e não sucumbir à pressão feita pela indústria fumageira deve ser a grande meta do governo com o suporte das instituições que tem compromisso com a população.

Em que pese o difícil caminho trilhado pela Anvisa e da aparente parada ou mesmo retrocesso no processo regulatório observado pela retirada de uma série de aditivos proibidos na RDC14/2012 para análises futuras, faz-se necessário notar que a sociedade precisa dar suporte para que a agência resista aos ataques e pressões contínuos e para que os Poderes Legislativo e Judiciário, com o suporte do Executivo, em especial do setor Saúde, sejam sensíveis à real necessidade de regulamentação de produtos do tabaco no Brasil, mantendo o mandato da Anvisa e permitindo que a RDC 14/2012 venha a ser cumprida e implementada em sua totalidade, conforme previsto em sua versão original.

Agradecimentos à Adriana Carvalho da ACTBR, por compartilhar informações mais recentes sobre os processos movidos contra a RDC14/2012 da Anvisa, e à Ana Paula Cardoso Richter do CETAB, pelo apoio no preparo do artigo.

\section{Referências}

AGÊNCIA NACIONAL DE VIGILÂNCIA SANITÁRIA (ANVISA), 2013. Gerência-Geral de Produtos Derivados do Tabaco (GGTAB) - competências. De 10 de dez. de 2013 [on line]. [data de consulta: 13 set. 2013] Disponível em: http://portal.anvisa.gov.br/wps/content/Anvisa+Portal/Anvisa/Agencia/Assunto+de+Int 
eresse/Estrutura+Organizacional/Gerencias+Gerais+de+Processos+Organizacionais/ Gerencia-Geral+de+Produtos+Derivados+do+Tabaco+--GGTAB

AGÊNCIA NACIONAL DE VIGILÂNCIA SANITÁRIA (ANVISA), 2013. Instrução Normativa $n^{\circ} 6$, de 26 de agosto de 2013, autoriza em caráter excepcional por 12 meses a utilização das substâncias constantes no Anexo desta Instrução Normativa. Diário Oficial da União, Seção 1, p. 81; 27 ago. 2013. [on line] [data da consulta: 01/11/2013] Disponível em: http://portal.anvisa.gov.br/wps/content/anvisa+portal/anvisa/sala+de+imprensa/menu+ +noticias+anos/2013+noticias/instrucao+normativa+atualiza+regra+sobre+aditivo+de +tabaco)

AGÊNCIA NACIONAL DE VIGILÂNCIA SANITÁRIA (ANVISA), 2013. Instrução normativa atualiza regra sobre aditivo de tabaco. Portal Anvisa, 2013. [online] [data da consulta: 18 set. 2013]. Disponível em: http://portal.anvisa.gov.br/wps/ content/anvisa+portal/anvisa/sala+de+imprensa/menu++noticias+anos/2013+noticias/ instrucao+normativa+atualiza+regra+sobre+aditivo+de+tabaco

AGÊNCIA NACIONAL DE VIGILÂNCIA SANITÁRIA (ANVISA), 2012. Resolução da Diretoria Colegiada - RDC $n^{\circ} 14$, de 15 de março de 2012, que 'dispõe sobre os limites máximos de alcatrão, nicotina e monóxido de carbono nos cigarros e a restrição do uso de aditivos nos produtos fumígenos derivados do tabaco, e dá outras providências'. [online]. [data de consulta: 23 jan. 2014] Disponível em: http://www.brasilsus.com.br/legislacoes/anvisa/112525-14.html.

AGÊNCIA NACIONAL DE VIGILÂNCIA SANITÁRIA (ANVISA), 2011. Suspensas audiências sobre produtos derivados do tabaco. Brasília : Portal Anvisa, 2011 [on line] [data da consulta: 18 set. 2013] Disponível em: http://portal.anvisa.gov.br/wps/portal/anvisa/anvisa/busca/lut/p/c5/jZBBDolwEEXPwgX oFIZCI4ixRQwVhYBsCBpDSCy4MBpvLz0AjfOXL3_-_CEtWTT173HoX-

M89Q_SkJZ1WSFTAeBxVUZbSLE8SZ4lakfpwisS0Q_sMTwAANskklogZ0GhAJT3jxtW JgbjXtktOFqzDbdn70k7XrX7uWkXXEDf8wMfKacYRjRCJLX5hb2b4ZbrcznrO3nqqmq$5-$

MQO84Pa78t3w!!/?1dmy\&urile=wcm\%3apath\%3a//Anvisa\%20Portal/Anvisa/Sala\%20 de $\% 20$ Imprensa/Assunto $\% 20$ de $\% 20$ Interesse/Noticias/Suspensas $\% 20$ audiencias $\% 20$ sobre $\% 20$ produtos $\% 20$ derivados $\% 20$ do $\% 20$ tabaco .

AGÊNCIA NACIONAL DE VIGILÂNCIA SANITÁRIA (ANVISA), 2010. DICOL. Consulta Pública $n^{\circ}$ 112, de 29 de novembro de 2010. [on line]. [data da consulta; 18 set. 2013] Disponível em: .http://brasilsus.com.br/legislacoes/consultapublica/106391-112.html

AGÊNCIA NACIONAL DE VIGILÂNCIA SANITÁRIA (ANVISA), 2001. Resolução da Diretoria Colegiada RDC $n^{\circ} 46$, de 2001, sobre 'Proposta de Revisão da RDC 46/2001 que trata sobre os teores de alcatrão, nicotina e monóxido de carbono nos cigarros, e a proibição de aditivos nos produtos derivados do tabaco e dá outras providências'. [online]. [data de consulta: 15 set. 2013] Disponível em: http://portal.anvisa.gov.br/wps/content/anvisa+portal/anvisa/regulacao+sanitaria/assun tos+de+interesse/consultas+publicas/assuntos+de+interesse/consultas+publicas+enc erradas/2010/20101130112 .

ALIANÇA PARA O CONTROLE DO TABAGISMO (ACTBr), 2012. Como as grandes empresas de tabaco usam dados duvidosos para minar as políticas de saúde. Rio de Janeiro. ACTBr, jul. 2012. ISBN: 978-1-872428-86-4 
ALIANÇA PARA O CONTROLE DO TABAGISMO (ACTBr), 2010. COP 4 aprova diretrizes dos artigos 9 e 10 da Convenção-Quadro para o Controle do Tabaco. São Paulo: ACTBr, 2010 [on line] [data da consulta: 12 set. 2013] Disponível em: http://actbr.org.br/uploads/conteudo/543_ARTIGOS_9_E_10.pdf. [ISBN: não disponível].

ALIANÇA PARA O CONTROLE DO TABAGISMO (ACTBr), 2010. Boletim Fatos em Destaque. Fatos sobre aromatizantes e sabores do tabaco: baseado em material da Framework Convention Alliance (FCA). São Paulo: ACTBr, 210 [on line] [data da consulta 10 fev.2014]. Disponível em: http://actbr.org.br/uploads/ conteudo/529_aromatizantes_2010.pdf [ISBN: não disponível].

ANDRADE, APA e SALES, MR., 2006. Prevalência e características do tabagismo em jovens da Universidade de Brasília. Jornal Brasileiro de Pneumologia; 32(1): 23-28, 2006. ISSN: $1806-3713$ (impresso); $1806-3756$ (on line).

ASSOCIAÇÃO BRASILEIRA DE BARES E RESTAURANTES SC (ABRASEL SC), 2011. Anvisa recebe 200 mil sugestões em consulta pública sobre cigarro. Florianópolis-SC: Abrasel, 2011. [on line] [data da consulta: 24 jan. 2013] Disponível em: http://www.abraselsc.com.br/noticias/item/339 .

ASSOCIAÇÃO BRASILEIRA DE ENTIDADES E EMPRESAS DE GASTRONOMIA, HOSPEDAGEM E TURISMO (ABRESI), 2009. Varejistas combatem propostas da Anvisa. Brasília- DF: Abresi, 2009. [on line] [data da consulta: 12 set. 2013] Disponível em: http://www.abresi.com.br/noticia_252.htm .

ASSOCIAÇÃO DOS FUMICULTORES DO BRASIL (AFUBRA). DF, 2011. Afubra presente nas duas audiências pública da Anvisa. Brasília : Página Rural, 2011 [on line] [data da consulta: 12 set. 2013] Disponível em: http://www.paginarural.com.br/noticia/162484/afubra-presente-nas-duas-audienciaspublica-da-anvisa .

BORNHAUSER, A; McCARTHY, J e GLANTZ, AS., 2006. German tobacco insdustry's successful efforts to maintain scientific and political respectability to prevent regulation of secondhand smoke. Tobacco Control; vol.15: ed. 2 pag. e1; abril de 2006. doi:10.1136/tc.2005.012336BRASIL. Presidência da república, 1988. Casa Civil. Constituição da República Federativa do Brasil. 1988. [on line] [data de consulta: 23 jan. 2014] Disponível em: http://www.planalto.gov.br/ ccivil_03/constituicao/constituicaocompilado.htm

BRASIL, Ministério da Agricultura, Pecuária e Abastecimento, 2004. Portaria 231 de 10/09/2004. Cria as Câmaras Setoriais e Temáticas. Ministério da Agricultura, 2004. [on line] [data da consulta 27 fev 2014]. Disponível em http://www.agricultura.gov.br/camaras-setoriais-e-tematicas

BRASIL, Ministério do Desenvolvimento, Indústria e Comércio Exterior, 2009. Portaria 60 de 03 de fevereiro de 2009: Câmara Setorial da Cadeia Produtiva do Tabaco [on line]. 2009 [data da consulta 27 fev 2014]. Disponível em:http://www.mdic.gov.br/sitio/interna/interna.php?area=1\&menu=3733

BRASIL. Ministério da Saúde, 2011. Secretaria de Vigilância em Saúde. Vigitel Brasil 2011: vigilância de fatores de risco e proteção para doenças crônicas por inquérito telefônico. Brasília : Ministério da Saúde, 2012. [on line] [data de consulta: 7 set. 2013] Disponível em: http://bvsms.saude.gov.br/bvs/publicacoes/ vigitel_brasil_2011_fatores_risco_doencas_cronicas.pdf . ISBN 978-85-334-2054-0. 
BRASIL. Câmara dos Deputados, 2011. Projeto de Lei n².901, de 2011, que 'dispõe sobre a restrição de inclusão de aditivos em produtos fumígeros em geral, derivados ou não do tabaco, comercializados em território nacional'. [on line] [data da consulta: 24 jan. 2014] Disponível em: http://www.camara.gov.br/proposicoesWeb/ fichadetramitacao?idProposicao=530864 .

BRASIL. Câmara dos Deputados, 2010. Projeto de Lei $n^{\circ} 3.034$, de 2010, que 'susta os efeitos da consulta pública da Anvisa no 112 de 29/08/10'. [on line] [data da consulta; 23 jan. 2014] Disponível em: http://www.camara.gov.br/proposicoesWeb/prop_imp;jsessionid=81AB1CA9BD8097B EA090C650D446D85F.node2 idProposicao $=489609$ \&ord=1\&tp=completa .

BRASIL. Ministério da Agricultura, 2010. Posicionamento do setor de tabaco sobre as Consultas Públicas $n^{\circ} 112$ e $n^{\circ} 117$ da Agência Nacional de Vigilância Sanitária. Documento sobre as decisões da Câmara Setorial do Tabaco [on line] [data da consulta: 12 set. 2013] Disponível em: http://www.agricultura.gov.br/arq_editor/file/camaras_setoriais/Tabaco/01_RE/App.pdf

BRASIL. Presidência da República. Casa Civil, 2003. Decreto Lei de 1 de Agosto de 2003 - Cria a Comissão Nacional para Implementação da Convenção-Quadro para o Controle do Tabaco e de seus Protocolos [on line]. Disponível em http://www.planalto.gov.br/ccivil_03/dnn/2003/Dnn9944.htm

BRASIL. Presidência da República. Casa Civil, 2011. Lei $n^{\circ} 12.546$, de 14 de dezembro de 2011. [on line]. [data de consulta: 18 set. 2013] Disponível em: http://www.planalto.gov.br/ccivil_03/_Ato2011-2014/2011/Lei/L12546.htm\#art49

BRASIL. Presidência da República, 2006. Casa Civil. Decreto $n^{\circ}$ 5.658, de 2 de janeiro de 2006, que 'promulga a Convenção-Quadro sobre Controle do Uso do Tabaco' [on line]. [data de consulta: 4 set. 2013] Disponível em: http://www.planalto.gov.br/ccivil_03/_Ato2004-2006/2006/Decreto/D5658.htm .

BRASIL. Presidência da República, 1990. Casa Civil. Código de Defesa do Consumidor (Lei no 8.078, de 11 de setembro de 1990). [on line] [data de consulta: 23 jan. 2014] Disponível em: http://www.planalto.gov.br/ccivil_03/LEIS/L8078.htm .

BRASIL. Presidência da República, 1996. Casa Civil. Lei $n^{\circ}$ 9.294, de 1996, que 'dispõe sobre as restrições ao uso da propaganda de produtos fumígeros, bebidas alcoólicas, terapias e defensivos agrícolas' [on line]. [data de consulta: 7 set. 2013] Disponível em: http://www.planalto.gov.br/ccivil_03/Leis/L9294.htm.

BRASIL. Presidência da República, 1999. Casa Civil. Lei $n^{\circ}$ 9.782, de 26 de janeiro de 1999, que 'define o Sistema Nacional de Vigilância Sanitária e cria a ANVISA'. [on line]. [data de consulta: 23 jan. 2014] Disponível em: http://legisweb.com.br/legislacao/?id=85269.

BRASIL. Presidência da República, 1999. Decreto Lei no 3.136, de 1999. Cria a Comissão Nacional para a preparação da participação do Brasil nas negociações internacionais com vistas à elaboração de convenção-quadro sobre controle do uso do tabaco e dá outras providências [on line]. Disponível https://www.google.com.br/search?q=Decreto $+n \% C 2 \% B A+3.136 \% 2 F 1999 \&$ ie $=u t f-$ $8 \& o e=u t f-8 \& a q=$ t\&rls=org. mozilla:pt-BR:official\&client=firefox\&channel=fflb\&gfe_rd=cr\&ei=_FYPU8utOImU8QfivICwCA

BRASIL. Supremo Tribunal Federal (STF), 2013. Ação Direta de Inconstitucionalidade (ADIN) $n^{\circ}$ 4.874. Requerente: Confederação Nacional da Indústria (CNI); intimados: 
Presidente da República; Congresso Nacional. Relator: Ministra Rosa Weber. Brasília, 2013. [on line] [data da consulta: 24 jan. 2014] Disponível em: http://www.stf.jus.br/portal/processo/verProcessoAndamento.asp?incidente $=4328586$

BRASIL. Tribunal Regional Federal da Primeira Região (TRF 1 DF), 2012. Ação movida pelo Sinditabaco. Autor: SINDICATO INTERESTADUAL DA INDÚSTRIA DO TABACO; Réu: Agência Nacional de Vigilância Sanitária - ANVISA; Relator: Juiz Alaor Piacini, 9a Vara. Brasília, 2012. [on line] [data da consulta: 03 set. 2013]. Disponível em: http://processual.trf1.jus.br/consultaProcessual/ processo.php?trf1_captcha_id=46ca6b15878a03d31ec341cfcda8bf22\&trf1_captcha $=7 z 2 X \&$ enviar=Pesquisar\&proc $=00468978620124013400 \&$ secao=DF

BRUNNEMANN, KD [et al], 1996. Tobacco-specific N-nitrosamines. Critical Reviews in Toxicology; 26(2):121-137, 1996. ISSN: 1040-8444 (impress); 1547-6898 (on line).

CASTRO, HA e COSTA E SILVA, VL., 2013. Proibição dos aditivos de produtos do tabaco em risco. Rio de Janeiro : Informe ENSP, 31/07/2013 [on line]. [data da consulta: 12 set. 2013]. Disponível em : http://www.ensp.fiocruz.br/portalensp/informe/site/materia/detalhe/33260 .

CHIAPETTA, S., 2013. Caracterização do tabaco empregado no Brasil por diferentes técnicas analíticas. [Tese de Doutorado]. Universidade Federal Fluminense (UFF); 2013.

MIGALHAS, 2012. Informe [on line]. CNI questiona atuação da Anvisa e contesta resolução sobre cigarros. Migalhas, 10 nov. 2012. [on line]. [data da consulta: 13 set. 2013]. Disponível em: http://www.migalhas.com.br/Quentes/17,MI167375,91041$\mathrm{CNI}+q u e s t i o n a+a t u a c a o+d a+A n v i s a+e+c o n t e s t a+$ resolucao+sobre+cigarros

FIGUEIREDO, VC.; COSTA e SILVA VL., CASADO L.; MASSON E.; CAVALCANTE T.; ALMEIDA LM.. Use of flavored cigarettes among Brazilian adolescentes: a step toward nicotine addiction. Poster presented at the 15th World Conference on Tobacco or Health (WCTOH), March 20, 2012, Singapore, Singapore.

FOLHA ONLINE, 2013: ANVISA libera aditivos com extrato de café para uso em cigarros.; 28 ago. 2013. [on line]. [data da consulta: 13 set. 2013]. Disponível em: http://www1.folha.uol.com.br/equilibrioesaude/2013/08/1333052-anvisa-liberaaditivos-como-extrato-de-cafe-para-uso-em-cigarros.shtml [ISSN: não disponível].

FUNDAÇÃO GETÚLIO VARGAS (FGV) PROJETOS, 2010. Estudo dos Efeitos Socioeconômicos da Regulamentação, pela Anvisa, dos assuntos de que tratam as Consultas Públicas $n^{\text {os }}$. 112 e 117 de 2010. Rio de Janeiro [on line]. [data da consulta:01 set. 2013]. Disponível em: http://fgvprojetos.fgv.br/publicacao/estudo-deefeitos-socioeconomicos-da-regulamentacao-dos-assuntos-das-consultas-publicas

INSTITUTO BRASILEIRO DE GEOGRAFIA E ESTATÍSTICA (IBGE), 2009. Pesquisa Nacional de Saúde do Escolar, 2009. Rio de Janeiro : IBGE, 2009. [on line] [data de consulta: 17 set. 2013] Disponível em: http://biblioteca.ibge.gov.br/visualizacao/livros/liv43063.pdf. ISBN: 9788524041075

INSTITUTO NACIONAL DE CÂNCER (INCA), 2011. Varejistas combatem propostas da Anvisa. Rio de Janeiro : INCA, 2011 [on line] [data da consulta: 12 set. 2013] Disponível em: http://www.inca.gov.br/tabagismo/atualidades/ver.asp?id=1652 . ISSN 1983-392X.

LEVY, D; ALMEIDA, LM. e SZKLO, A., 2012. The Brazil SimSmoke policy simulation model: the effect of strong tobacco control policies on smoking prevalence and 
smoking-attributable deaths in a middle income nation. PLoS Medicine; 9(11):e1001336, 2012. ISSN: 1549-1277.

MOLINA, D., 2011. Avançam discussões sobre restrições para derivados do tabaco. Brasília : Portal Anvisa, 2011. [on line] [data da consulta: 18 set. 2013] Disponível em: http://portal.anvisa.gov.br/wps/portal/anvisa/anvisa/busca/lut/p/c5/jZBBDolwEEXPwgX oFIZCI4ixRQwVhYBsCBpDSCy4MBpvLzOAjfOXL3_-_CEtWTT173HoX-

M89Q_SkJZ1WSFTAeBxVUZbSLE8SZ4lakfpwi-

sS0QsMTwAANskklogZ0GhAJT3jxtWJgbjXtktOFqzDbdn70k7XrX7uWkXXEDf8wMfK acYRjRCJLX5hb2b4ZbrcznrO3nqqmq-5-

MQO84Pa78t3w!!/?1dmy\&urile=wcm\%3apath\%3a//Anvisa\%20Portal/Anvisa/Sala\%20 de\%20Imprensa/Menu\%20-

\%20Noticias\%20Anos/2011\%20Noticias/Avancam\%20discussoes\%20sobre\%20restri coes $\% 20$ para $\% 20$ derivados $\% 20$ do $\% 20$ tabaco .

MONTEIRO, CA [et al], 2007. Population-based evidence of a strong decline in the prevalence of smokers in Brazil (1989-2003). Bulletin of the World Health Organization; 85(7):535-544, jul. 2007. [online]. [data de consulta: 4 set. 2013] Disponível em: http://www.fsp.usp.br/nupens/smokers.pdf . ISSN: 0042-9686

ORGANIZAÇÃO MUNDIAL DA SAÚDE (OMS), 2013. WHO Report on the Tobacco Epidemic, 2013. Executive Summary. Genebra : Organização Mundial da Saúde, 2013 (WHO/NMH/PND/13.2). [on line]. [data de consulta: 4 set. 2013] Disponível em: http://www.who.int/tobacco/global_report/2013/en_summary.pdf ISBN: 978924 0691605

ORGANIZAÇÃO MUNDIAL DA SAÚDE (OMS), 2013. Fourth session of the Conference of the Parties to the WHO FCTC - COP 4. Genebra : OMS, 2010. [on line] [data da consulta: 17 set. 2013] Disponível em: http://www.who.int/fctc/cop/sessions/fourth_session_cop/en/. ISBN: 978924069161 2

ORGANIZAÇÃO MUNDIAL DA SAÚDE (OMS), 2010. Partial guidelines for implementation of Articles 9 and 10. Genebra : OMS, 2010. [on line] [data da consulta: 17 set. 2013] Disponível em: http://www.who.int/fctc/guidelines/ adopted/article_9and10/en/. ISBN: 9789241505185

ORGANIZAÇÃO MUNDIAL DA SAÚDE (OMS), 2006. First session of the Conference of the Parties to WHO FCTC. Genebra : OMS, 2006. [on line] [data da consulta: 17 set. 2013] Disponível em: http://www.who.int/fctc/cop/sessions/ first_session_cop/en/.ISBN: 978-85-7318-155-5

ORGANIZAÇÃO MUNDIAL DA SAÚDE (OMS), 2004. International Agency for Research on Cancer (IARC). Tobacco smoking and involuntary smoking. Genebra: Editor: Heidi Mattock, 2004. Monographs on the Evaluation of Carcinogenic Risks to Human. [on line] [data da consulta: 5 set. 2013] Disponível em: http://monographs.iarc.fr/ENG/Monographs/vol83/volume83.pdf ISBN 9283212835

ORGANIZAÇÃO MUNDIAL DA SAÚDE (OMS), 2003. WHO Framework Convention on Tobacco Control. Genebra: OMS, 2003. [on line] [data da consulta: 01 set. 2013] Disponível em: http://www.who.int/fctc/text_download/en/. ISBN: 9241591013

ORGANIZAÇÃO PAN-AMERICANA DA SAÚDE (OPAS); Johns Hopkins Bloomberg School of Public Health; Tobacco Free Kids e Aliança para o Controle do Tabagismo, 2010. Análise do "Estudo dos Efeitos Socioeconômicos da Regulamentação, pela ANVISA, dos Assuntos de que tratam as Consultas Públicas no. 112 e 117, de 2010", 
assinado pela Fundação Getúlio Vargas. [s.I.; s.n.; s/d.] [on line] [data da consulta: 23 dez. 2013] Disponível em: http://actbr.org.br/uploads/conteudo/ 664_RESPOSTA_FGV.pdf. [ISBN: não disponível].

PARTIDO PROGRESSISTA, 2011. Renato Molling incluirá restrições ao cigarro em medida provisória. Brasília : Partido Progressista, 2011. [on line]. [data da consulta: 12 set. 2013] Disponível em: http://www.pp.org.br/noticias/453/ 149582/RenatoMollingIncluiraRestricoesAoCigarroEmMedidaProvisoria/ .

PINTO, M. e UGA, MA., 2010. Os custos de doenças tabaco-relacionadas para o Sistema Único de Saúde. Cadernos de Saúde Pública; 26(6):1234-45, jun. 2010. ISSN 0102-311X.

ROMERO, L.C.P.; COSTA E SILVA, V.L. 23 Anos de Controle do Tabagismo no Brasil: a Atualidade do Programa Nacional de Combate ao Fumo de 1988. Revista Brasileira de Cancerologia, 57:305-314, 2011. [on linet]. [data de consulta: 21 maio 2013]. Disponível em: http://www.inca.gov.br/rbc/n_57/v03/pdf/ 03_artigo_23_Anos_controle_tabaco_brasil_atualidade_programa_nacional_combate _fumo_1988.pdf

SCHIMIDT, MI [et al.], 2011. Chronic non-communicable diseases in Brazil: burden and current challenges. The Lancet; 377(9781):1949-1961, 4 jun. 2011. [on line] [data de consulta: 7 set. 2013] Disponível em:

http://download.thelancet.com/pdfs/journals/lancet/PIIS0140673611601359.pdf?id=41 0a13c7e856fa01:-18859443:140e9366f28:62d11378307018232. ISSN: 0140-6736 SZKLO, AS [et al.], 2012. A snapshot of the striking decrease in cigarette smoking prevalence in Brazil between 1989 and 2008. Preventive Medicine; 54(2):162-167, fev. 2012. ISSN: 0091-7435.

WILTON CASTRO, 2013. Advocacia Geral da União defende no STF competência da Anvisa para proibir uso de aditivos com sabor em cigarros. Jus Brasil. 2013 [on line] [data da consulta: 20 de set.de 2013] Disponível em: http://agu.jusbrasil.com.br/noticias/100430053/agu-defende-no-stf-competencia-daanvisa-para-proibir-uso-de-aditivos-com-sabor-em-cigarros 